\title{
LOS CUENTOS CRUELES DE SILVINA OCAMPO Y JUAN RODOLFO WILCOCK
}

\author{
POR \\ DANIEL BALDERSTON \\ Tulane University
}

Una idea central de la literatura fantástica argentina: que la literatura no representa ni copia una realidad exterior, sino que crea una verosimilitud textual. Es decir, una celebración de la idea de que la literatura es algo artificial, que no nos importa por su relación con la realidad o con la vida, sino por su diferencia esencial respecto de ellas (como dice Stevenson en "A Humble Remonstrance» ${ }^{1}$ ). Sin embargo, dos escritores argentinos vinculados a Sur y a Borges y Bioy cuestionan el énfasis en lo fantástico llevándolo a sus últimas consecuencias. Juan Rodolfo Wilcock y Silvina Ocampo aceptan la idea de que el mundo textual está hecho de palabras y no de experiencias, y que depende más de la imaginación del lector que de su memoria. Sin embargo, por haber introducido en sus obras narrativas elementos de una crueldad sádica, hacen que el lector sienta la afinidad entre el mundo creado y el mundo real de la experiencia; mejor dicho, hacen que el lector sienta el horror de las situaciones inventadas como si se sufrieran en carne propia. El sadismo, enmarcado siempre por la doble búsqueda del dolor y del placer, lleva a estos dos escritores - unidos por la amistad y por sus colaboraciones en el mundo literario- a abandonar una estética en que la belleza se ve como algo decoroso, lujoso, discreto, para plantear la posibilidad de otra belleza, estrechamente ligada al horror.

Wilcock y Ocampo -dos escritores argentinos nunca consagrados por la crítica que ha elogiado a tantos de sus contemporáneos, nunca aceptados plenamente por un público más bien pasivo en sus gustos literarios-, dejados de lado tal vez por motivos biográficos (los vínculos

${ }^{1}$ Stevenson, Works, Thistle Edition (Nueva York: Scribner's, 1897), tomo XIII, p. 350; traducción mía. 
familiares de Ocampo a otros escritores de más renombre pero muy distintos de ella, la brusca partida de Wilcock de la Argentina en el año 56 y su obra posterior en italiano), tal vez porque sus textos no corresponden siempre a ideas establecidas sobre el buen gusto literario. Son textos que especialmente violan todo decoro y asaltan al lector imaginativo por su interés en la crueldad, aunque el lector tenga en cuenta que sólo se trata de un objeto artificial, de lo que Borges llama una «superficie de imágenes». Un interés por la crueldad compartido con otros escritores de su generación como Virgilio Piñera y José Bianco, y con escritores importantes de generaciones más jóvenes como Juan José Hernández y Osvaldo Lamborghini. En todo caso, un abandono con el que la crítica debe acabar, ya que impide la comprensión de la literatura fantástica argentina (que tanto ha influido en otras literaturas mundiales) en su totalidad, en esa totalidad que le permite pasar fácilmente de lo fantástico a lo grotesco, de lo grotesco a lo ridículo o lo metafísico.

La crueldad de Wilcock y Ocampo es a menudo una crueldad teatral al estilo de Artaud (aunque pasada a la hoja plana de la página literaria), de ese Artaud que proclamaba: "La imagen de un crimen presentada en las condiciones teatrales necesarias es algo infinitamente más temible para el espíritu que el mismo crimen realizado" ${ }^{2}$. Crean escenarios plenamente irreales para luego realizarlos con detalles terroríficos o risibles: el narrador de «El caos», por ejemplo, está sentado en su silla de ruedas mirando el mar cuando se derrumba el precipicio donde está ubicado, y observa: «Quién se hubiera imaginado que en el instante mismo en que yo creía por fin desprenderme de la tierra, era la tierra la que se desprendía de mí» $(C, 20)^{3}$. El cuento más cruel de Wilcock (y uno de los más crueles de la lengua castellana, comparable con «E1 fiord» de Lamborghini) es "La fiesta de los enanos», relato de un espectáculo sádico que se convierte en orgía carnavalesca. Los enanos del cuento, Présule y Anfio, viven en una paz ritualizada con una viuda rica, Güiendolina, contando historias, inventando jueguitos y comiendo su manjar preferido, el pescado enlatado (que les inspira una "pasión casi irracional», según el narrador: $C, 38$ ), hasta que esta vida feliz y retirada se interrumpe con la irrupción de Raúl, un sobrino de la señora que pronto se convierte en su amante. Los enanos, desquiciados por una

${ }^{2}$ Le théatre et son double (Paris: Gallimard, 1964), p. 131; traducción mía.

${ }^{3} \mathrm{C}$ en el texto se refiere a $\mathrm{El} \mathrm{caos}$, de Wilcock (Buenos Aires: Sudamericana, 1974). Wilcock tradujo estos cuentos al italiano -Parsifal: I racconti del «Caos» (Milano: Adelphi, 1974) - , pero me limito a hablar aquí de las versiones originales en castellano. 
relación que los excluye, tratan de envenenar a Raúl, pero es la señora quien bebe el chocolate envenenado; muerta la señora, matan a Raúl de manera que anticipa los métodos de la llamada «lucha contra la subversión» de los últimos años: con cuchillo de caza y soldador eléctrico despedazan al muchacho, sintiendo que «la vista de la sangre los excitaba estéticamente» $(C, 62)$. Un párrafo típico de la descripción de la fiesta sádica:

Excitado extrañamente por el color de la sangre, [Présule] volvió a empuñar el soldador, murmurando entre dientes: «Para qué sirve la nariz, para qué sirve la nariz.» Por un resabio de consideración humana ponía especial cuidado en agrandar progresivamente los agujeros a medida que la destrucción avanzaba, para que no le faltara el aire. Los gemidos del muchacho, el cual muy probablemente ya se había tragado el menisco que los enanos le habían introducido en la boca para calmarlo [después de habérselo cortado de la rodilla derecha], aumentaron otra vez hasta convertirse en aullidos permanentes $(C, 62)$.

Lo desconcertante de esta descripción no es la crueldad en sí - la literatura de nuestro siglo abunda en hechos crueles, como nuestra historia-, sino el placer evidente que el narrador comparte con los enanos, y la manera en que este placer se mezcla con una especie de pudor (véase, por ejemplo, la mención del «resabio de consideración humana»). Un narrador que observa la variedad de sentimientos humanos que motivan a los enanos —odio, envidia, misericordia, placer sexual, pudory que se excita junto con ellos sin criticarlos en ningún momento. $Y$ un narrador que terminará su relato con una descripción aún más desconcertante de la comida orgiástica con la que los enanos celebran la muerte de su rival odiado - enumeración detallada de una mezcla de pescados enlatados con numerosos licores- y que comentará: «El deleite los exaltaba por encima de las miserias de la carne, más allá del presente y del pasado, en un futuro que bien podría ser eterno; el pescado resolvía las contradicciones de la realidad» $(C, 63)$. Tanto como la comida - una mezcla de salmón, anchoa y arenque con vino, caña, anís, vodka y marsala al huevo-, lo que preside esta narración parece ser la idea de mezclar ingredientes inesperados: humor, crueldad, pasión sexual y pasión metafísica. Hay un exceso notable en el relato, que sobrepasa (y casi deja de 1ado) el motivo original de los hechos crueles -el odio hacia el intruso-, para gozar del acto de torturar en sí, y que se complacerá pensando que después de acabar con las latas, los enanos podrán subsistir comiendo los cadáveres de la señora y de Raúl.

A pesar de sus nombres inverosímiles, Présule, Anfio y Güendolina viven en un apartamento muy fácil de imaginar de la calle Solís de Bue- 
nos Aires, uno de aquellos apartamentos amueblados según los gustos de la generación del 80 , con su juego de comedor de nogal oscuro, traído de Francia $(C, 40)$, con sus colchas con flecos y su jardín rodeado de altos muros. Las contradicciones de la vida argentina parecen irreales en su esencia ${ }^{4}$. La irrealidad expresada en este cuento dista mucho del cuidadoso mundo irreal de Borges y de Bioy, ya que se hace a base de exageración en vez de ironía, de violaciones de la imaginación del lector más que de esfuerzos de seducir su fantasía. La fiesta sádica de Wilcock va más allá de esa irrealidad que, según Borges, es condición del arte: llega hasta un mundo irreal donde las contradicciones de la realidad se resuelven grotescamente, donde el placentero reino de la literatura fantástica se ve amenazado por una violencia textual.

Varios cuentos de Silvina Ocampo indagan ese mundo burgués de Buenos Aires, que se revela (como en el cuento de Wilcock que acabo de comentar) escenario ideal para hechos fantásticos o grotescos, ya que siempre ha sido un mundo más pensado que realizado. En «La casa de azúcar», una casa aparentemente ideal resulta haber pertenecido a una mujer que murió cuando otra persona le robó la vida, y que se venga de esa persona cuando va a vivir a su casa. En «Los objetos», las cosas que Camila Ersky ha perdido a lo largo de su vida vuelven para atormentarla. Pero la indagación más despiadada en el mundo pequeñoburgués bonaerense se da en el cuento «Las fotografías», en el que una fiesta familiar de cumpleaños es escenario de una crueldad teatral. La festejada es una muchacha, Adriana, que se ha quedado paralítica después de una larga enfermedad. La llegada del fotógrafo, Spirito, es pretexto para que la familia ensaye un espectáculo que acabará siendo la muerte de la muchacha. Cada cual insiste en que el fotógrafo tome cierta foto que, según su criterio, es esencial (Adriana con un abanico negro, Adriana con el abuelo «que tanto la quiere» $[F, 75]^{5}$, Adriana con los botines puestos en los pies paralíticos, que, según el fotógrafo, «si quedan mal, después se los corto» $[F, 74]$ ), hasta el momento en que Adriana se queda aparentemente dormida, la cabeza colgando «de su cuello como un melón» $(F, 76)$. La crueldad del cuento se revela ya desde el comienzo: Albina Renato baila «La muerte del cisne» «para hacernos reír» $(F, 72)$, los huéspedes se entretienen «contando cuentos de accidentes más o menos fatales» $(F, 73)$. Adriana trata de expresar

"Véase también «La noche de Aix", en donde el sueño de un argentino radicado en Francia se describe así: «La escena irreal empezaba ya a incorporarse a la colección de escenas reales que aún conservaba de su país distante» $(C, 109)$.

${ }^{5} F$ en el texto se refiere a la tercera edición de La Furia, de Ocampo (Buenos Aires: Orión, 1976). 
su desagrado ante esta manera brutal de festejarla, y hace una mueca de dolor cuando el fotógrafo propone cortarle los pies si quedan mal, pero nadie le hace caso.

$\mathrm{Si}$ «La fiesta de los enanos» presenta una mezcla de sentimientos humanos básicamente discretos, «Las fotografías» muestra un desplazamiento de sentimientos. Lo que quiere ser ternura se revela como egoísmo («Nos hemos desvivido por ella», dice la tía: $F, 75$ ), lo que quiere ser entretenimiento se revela como una crueldad tal vez inconsciente ( La muerte del cisne», bailada de manera grotesca en la fiesta de cumpleaños de una muchacha paralítica). El ejemplo definitivo de este desplazamiento: la ternura que todos dicen y creen sentir para con la muchacha se muestra en gestos que la niegan: por insistir en que Spirito saque un número excesivo de fotos, mortifican el espíritu y la carne de la muchacha a tal grado que acaban por matarla. El narrador del cuento no critica a los parientes de Adriana por lo que podríamos llamar su hipocresía y su egoísmo, sino que echa toda la culpa de la «tragedia» a «la desgraciada de Humberta», «esa aguafiestas» $(F, 76)$, quien agua la fiesta principalmente por descubrir que la festejada ha muerto. Ese juicio algo injusto hacia Humberta se debe tal vez a lo que algunos críticos han llamado la inocencia o la ingenuidad de los narradores de los cuentos de Silvina Ocampo ${ }^{6}$, aunque también es posible que sea un desplazamiento de lo que tal vez sienta el narrador (como todos, cómplice en la muerte de Adriana por no fijarse en el sufrimiento y cansancio de la muchacha, pero tal vez el más culpable por haber sido quien se da cuenta del hecho de que la muchacha aparentemente quiere pedir un vaso de agua poco antes de desmayarse, pero que no hace nada para satisfacer su pedido). Como en "La fiesta de los enanos", no hay ironía o crítica acerca de la crueldad central del cuento (no la de Humberta, sino la del grupo entero); si hay perspectiva irónica, surge de la distancia entre el narrador «inocente» o mendaz y el universo moral «normal» de autora y lectores.

Esa distancia irónica entre narrador ingentio y crueldad de lo narrado es rasgo central de la narrativa de Silvina Ocampo. Algunos narradores de los relatos de la escritora son niños («El moro», «La boda», «La casa de los relojes») que parecen apenas entender lo que narran; otros, aunque adultos, por alguna deficiencia de ingenio tampoco logran entender lo que pasa a su alrededor ("La Furia», «La casa de azúcar»).

${ }^{6}$ Véase Sylvia Molloy, «Simplicidad inquietante en los relatos del Silvina Ocampo», en Lexis, vol. II, núm. 2, (diciembre 1978), pp. 241-251, y Eduardo Cozarinsky, introducción a Informe del cielo y del infierno (Caracas: Monte Avila, 1970), sobre todo la p. 13. 
Como el Dios de Mill mencionado en un ensayo de Borges, la ironía acecha o se insinúa en los intervalos entre esa inocencia del que cuenta y lo atroz de lo que se cuenta. No hay mejor ejemplo que «La casa de los relojes»: el narrador infantil le escribe una carta a su profesora describiendo la fiesta en que unos vecinos borrachos deciden planchar el traje arrugado del relojero jorobado cuando lo tiene puesto. Evidentemente, el niño no entiende exactamente qué pasa -aunque vomita cuando los ve planchar la giba-, ya que le pregunta después a su madre adónde se ha ido el relojero. (Ella contesta que se fue «a otra parte»: $F, 47)$. El horror del niño - lo que lo hace vomitar- se deriva de que presencia un hecho que excede su comprensión, pero que de todas maneras no le gusta (observa, por ejemplo, que el relojero ríe nerviosamente antes de la operación, pero que los demás adultos ya no ríen). Nuestro horror, en cambio, procede en gran parte del hecho de que sea un niño el testigo del hecho horroroso: que los adultos sádicos no sólo deciden plancharle la giba al relojero, sino que también dejan que el niño vea la operación, causando no sólo un daño físico (la muerte del relojero), sino también un daño psíquico (el trauma infantil). E1 hecho inverosímil (o fantástico) - la decisión de planchar la giba- se vuelve realidad atroz a través de una narración fragmentada, ya que el niño - sin entender nada de lo que pueda motivar al jorobado a dejar que le planchen la giba, ni de lo que pueda tener de entretenido para los demás el hacerlo- es capaz de observar todos los hechos consumados, de decirnos lo que pasa sin explicárnoslo. Es precisamente el tipo de narración fragmentada que propone Borges en «La postulación de la realidad» - la de «imaginar una realidad más compleja que la declarada al lector y referir sus derivaciones y efectos» ${ }^{7}$-, salvada la diferencia de que la complejidad excluida del relato de Silvina Ocampo, pero plenamente imaginada por su lector, es esa psicología cuya existencia Borges ni siquiera quiere admitir. También vale la pena mencionar que ni el hecho cruel de este cuento, ni los de «La fiesta de los enanos» de Wilcock, podrían pasar de ninguna manera en el universo fantástico pero básicamente decoroso de Borges y Bioy ${ }^{8}$.

${ }^{7}$ Discusión (Buenos Aires: Emecé, 1964), p. 71.

${ }^{8}$ El propio Borges se maravilla ante la crueldad de Ocampo, y propone una explicación muy dudosa: «En los relatos de Silvina Ocampo hay un rasgo que aún no he llegado a comprender: es su extraño amor por cierta crueldad inocente u oblicua; atribuyo ese rasgo al interés, al interés asombrado que el mal inspira a un alma noble»: prefacio a la antología Faits divers de la Terre et du Ciel (Paris, 1974), traducción de Enrique Pezzoni en su artículo "Silvina Ocampo: la nostalgia del orden», en Sitio, núm. 1 (diciembre 1981), p. 110. 
La narración ingenua de hechos crueles o grotescos es característica también de la narrativa de Wilcock. Un ejemplo sencillo es lo que dice el príncipe que narra «El caos» cuando sus súbditos lo desnudan y lo atan a un asador:

Por suerte no se les había ocurrido atravesarme con el asador, como suelen hacer con los pollos, y además las brasas del fogoncito abierto despedían un agradable calor, que hacía más tolerable mi total desnudez, tan inadecuada en realidad a la estación. Un hombre de anchas barbas negras, vestido como un gitano, hacía girar en esos momentos la manivela del asador, con un lento movimiento circular que me permitía observar más cómodamente todo lo que ocurría en torno $(C, 14)$.

La ingenuidad o locura del narrador reside en su esfuerzo de buscar lo positivo en toda situación, por difícil que sea: que la desnudez se vea compensada por el calor del fuego, que al menos el asador no lo atraviesa. Ese positive thinking se revela totalmente absurdo en la descripción del movimiento circular, ya que es difícil admitir que fuese cómodo o deseable que el personaje observara lo que pasa en torno suyo. Si en los relatos de Silvina Ocampo el lector reconoce la desproporción entre el narrador inocente y la crueldad de lo narrado, y reacciona ante ella, frente al cuento de Wilcock su reacción bien puede ser distinta. La crueldad, en este cuento, no sirve para crear una verosimilitud textual (una «realidad») dentro de una situación básicamente inverosímil (como en «La casa de los relojes»), sino para sobrepasar realidad e irrealidad en una meditación sobre cuestiones metafísicas. El relato, que tiene como epígrafe una frase de Schroedinger, "La tendencia natural de las cosas es el desorden» $(C, 7)$, comienza con la confesión del narrador: «Desde muy chico me atrajo la filosofía» $(C, 7)$, y gira en torno a la relación problemática entre orden y caos. El encuentro con la violencia, la crueldad y el caos de que es víctima el narrador lo hace pensar (en el asador, en el mar cuando la tierra «se desprende» de él, en el nido del águila marina) en el destino del hombre en un mundo caótico (una parodia, tal vez, de las «situaciones-límites» de la literatura del existencialismo, de moda cuando Wilcock escribió este cuento). Su lección: «la omnipresencia de la nada, la suprema inexistencia de nuestra existencia» $(C, 25)$ - que se enseña en las fiestas caóticas que celebra para su gente, donde en las que «todo está mezclado, superpuesto, confundido» $(C, 31)$ - , se da al participante ( $\mathrm{y}$ al lector) no a través de una distancia irónica (como en ciertos relatos de Silvina Ocampo), sino por un súbito hundimiento en ese caos donde las cosas y las ideas ya no se dis- 
tinguen. La técnica más importante para enseñar esta lección a su gente es la sorpresa, sobre todo la sorpresa cruel (los sándwiches de gusano, los alambres tendidos a treinta centímetros del suelo en las salas de baile, las trampas en el jardín), porque hace que los participantes entrevean el caos del que sale, y al que vuelve, el orden.

Entrever, vislumbrar, espiar: verbos y acciones importantes en los relatos de ambos escritores, ya que permiten penetrar o violar el secreto ajeno y luego guardarlo para el propio placer. Ya en Sade, el mironismo sirve para aumentar el placer de la crueldad (véase, por ejemplo, la descripción que hace Barthes del teatro de Silling ${ }^{9}$ ): la crueldad, espectáculo de sí misma, necesita de la reflexión y la distancia para disfrutarse plenamente. En Wilcock y Ocampo se produce con frecuencia una especie de placer sexual en escenas en que el narrador espía un acto sexual (verbigracia, «Diálogos con el portero» y «La fiesta de los enanos», de Wilcock; «El pecado mortal» y «Los mastines del templo de Adriano», de Ocampo); habría que añadir que, muchas veces, haber visto el acto de amor lleva a los espectadores a destruir a los amantes (los enanos matan a la señora y a Raúl, los mastines destrozan a la pareja). Y aun cuando lo entrevisto no sea una unión sexual, sino cualquier tipo de vida secreta que excluya a los mirones, éstos reaccionan a menudo destruyendo a los que han visto (el niño incendia el cuarto donde están las madres el día de su cumpleaños en «Voz en el teléfono», la niña en «La boda» pone una araña venenosa en el rodete de la novia). La mirada es peligrosa, ya que enlaza al que ve con lo que ha visto, como descubre la narradora de «La oración» cuando espía el juego de un niño que se divierte ahogando a uno de sus compañeros:

Yo miraba la escena, como en el cinematógrafo, sin pensar que hubiera podido intervenir. Cuando el niño soltó la cabeza de su adversario, éste se hundió en el barro silencioso. Hubo entonces una desbandada. Los niños huyeron. Comprendí que había asistido a un crimen, a un crimen en medio de esos juegos que parecían inocentes $(F, 174)$.

El espiar un crimen hace del espectador un cómplice, el espiar un acto de amor crea la voluntad de matar a los amantes: el mironismo de Wilcock y Ocampo se relaciona frecuentemente con la violencia o la violación. (En «El pecado mortal», por ejemplo, ver el sexo del criado por la cerradura logra «la imposible violación de tu soledad»: $I, 141)^{10}$.

'Sade, Fourier, Loyola, traducción de Richard Miller (New York: Hill and Wang, 1976), pp. 146-148.

${ }^{10} I$ en el texto se refiere a Las invitadas (Buenos Aires: Losada, 1961). 
Enrique Pezzoni ha observado en un artículo reciente sobre La Furia que en los relatos de Silvina Ocampo se juega a menudo con la magia, pero que el poder del mago suele ser un "don sobrenatural inservible» ${ }^{11}$. Camily Ersky se siente humillada por los objetos que redescubre, Leopoldina -la que sueña con cosas que luego aparecen en el mundo de la vigilia - no sabe soñar con cosas valiosas o útiles, Magush y su amigo no saben qué hacer con los destinos que ven en las ventanas del edificio abandonado. La brujería frustrada se reduce a una especie de mironismo que ni siquiera provee placer al brujo. En los relatos de Wilcock y Ocampo no se produce la unión sexual porque al tocarse los cuerpos se destruyen, no da placer el mironismo porque el espectador siente la necesidad de destruir lo que ve, no sirve la brujería porque no se puede hacer nada con lo que se aprende a través del poder arcano. Es decir, cualquier intento de contacto entre el yo y el otro se ve frustrado por el placer del crimen o del dolor del aislamiento.

El ejemplo clave de esta búsqueda frustrada del contacto con el otro, que no se satisface con placer ni con dolor, es «La engañosa», de Wilcock. El narrador, contador de una cooperativa olivarera en San Rafael, se enamora de una española, Concha, quien trabaja en la cooperativa y despierta en los jóvenes «una inexplicable atracción que subvertía nuestro habitual aburrimiento, y nos hacía olvidar el exceso de olivos que nos rodeaba» $(C, 120)$. Concha es «de cintura de cántaro y caderas de guitarra, ojos ardientes, saliva dulce, fresca, abundante» $(C, 120)$ : las descripciones convencionales ya se ven obligadas a alternar con otras nuevas y grotescas. Cuando el muchacho le toca el seno, éste se deshace, dejando ver una especie de hormiguero que huele «a pis de gato» $(C, 124)$; cuando le toca las nalgas, los dedos «se hundieron inesperadamente en tres o cuatro agujeros; al introducir el índice curioso en uno de esos orificios inexplicables, sentí que una corona de dientecitos me lo mordía» $(C, 124)$. Al tocarla, en su frenesí pone la mano en una trampa para conejos, recibe descargas eléctricas en todo el cuerpo, no sabe al besarla «si era su lengua $o$ algún otro animal lo que se debatía espasmódicamente en mi boca» $(C, 125)$. Decide dejarla para salvarse la vida, aunque piense después que «esos minutos de desenfreno... [eran] en el fondo (¿por qué negarlo?) placenteros» $(C, 127)$. Termina el cuento: «Después, como siempre sucede, el destino nos separó, truncando un idilio que de todos modos no nos habría convenido

${ }^{11}$ Pezzoni, «Silvina Ocampo: la nostalgia del orden», p. 111. El mismo ensayo sirve de prólogo a una reciente edición española de La Furia (Madrid: Alianza, 1982), pp. 9-23. 
llevar a término» $(C, 127)$. "La engañosa» es el ejemplo más extremo de un rasgo típico de los relatos de Ocampo y Wilcock: el placer y el dolor se ven tan estrechamente ligados que sólo se podrá alcanzar el máximo placer (la unión con la Concha, en todas sus connotaciones) pagando con la muerte; de otro modo se queda para siempre en la búsqueda frustrada de placer y dolor parciales.

En el poema «Easter 1916», Yeats habla del comienzo de una nueva belleza, una belleza terrible. Wilcock y Ocampo, insatisfechos con la belleza convencional, la cual les parece cursi y aburrida (verbigracia, «La gallina de membrillo», de Ocampo ${ }^{12}$ ), también buscan una belleza que nace de la unión del placer con el dolor. El narrador de «Tales eran sus rostros» dice, con respecto a los sordomudos alados que se tiran del avión: «En realidad no se sabe si era horrible y se volvía hermoso, o si era hermoso y se volvía horrible» $(I, 8)$. Esta hermosura horrible que se da a través de momentos crtteles o grotescos es de una «intensa belleza» $(I, 11)$ nueva e interesante; es también una hermosura sumamente precaria, que sólo se produce en su amplitud con la muerte de sujeto u objeto. Esa condición precaria se describe muy bien en Los traidores, la obra de teatro que escribieron juntos Wilcock y Ocampo:

El placer y el dolor que dan los crímenes como los combustibles más ardientes con el tiempo se tornan en cenizas ${ }^{13}$.

${ }^{12}$ Véase el prólogo de Cozarinsky, pp. 9-10.

${ }^{13}$ Wilcock y Ocampo, Los traidores (Buenos Aires: Editorial Losange, 1956), p. 78 . 